\title{
INVESTIGATION OF BREAKWATER STABILITY AT PRESQUE ISLE PENINSULA ERIE, PENNSYLVANIA
}

by

Peter J. Grace

Coastal Engineering Research Center

DEPARTMENT OF THE ARMY

Waterways Experiment Station, Corps of Engineers

PO Box 631, Vicksburg, Mississippi 39181-0631

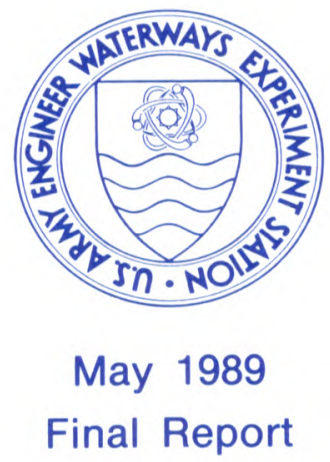

Approved For Public Release; Distribution Unlimited

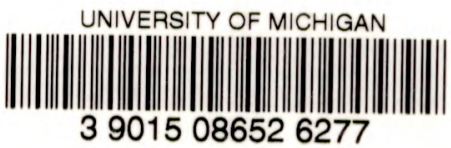

Prepared for US Army Engineer District, Buffalo 1776 Niagara Street

Buffalo, New York 14207-3199

Under Intra-Army Order NCB-1A-88-34JM 